\title{
Innovation Strategies, First Mover Advantage and Performance in the Context of the Microfinance Sector: A Review of Literature
}

\author{
Paul Ouma ${ }^{1} \&$ James M. Kilika ${ }^{2}$ \\ ${ }^{1}$ Doctoral Student, Department of Business Administration, School of Business, Kenyatta University, Kenya \\ ${ }^{2}$ Lecturer, Department of Business Administration, Kenyatta University \\ Correspondence: James M. Kilika, Department of Business Administration, School of Business, Kenyatta \\ University. Kenya. E-mail: kilikam3@yahoo.com
}

Received: April 25, 2018

doi:10.5539/ijbm.v13n7p195
Accepted: May 20, 2018

Online Published: June 15, 2018

URL: https://doi.org/10.5539/ijbm.v13n7p195

\begin{abstract}
The prevailing business environment is erratic and unreliable. The accomplishment of trade in such environment is determined by an organization's capability to adjust and respond to environmental variation. Innovation strategies offer a strategic option that can be used to align organization's assets and competencies with prospects in the external environment in order to heighten survival and long term success of an enterprise. Execution of such a strategic option is likely to result in strategic moves that will register impacts in the market which requires decision makers to consider the timing of their moves that operationalize the strategy in the market. The extant literature has pursued discussions on the construct of innovation strategy separately from that of first mover in spite of the implied indications that the two can be integrated into a strategic management phenomenon that will influence the firm's performance. This study provides a review of existing theoretical and empirical literature on the perspectives connected to innovation strategies as a strategic option, first mover advantage in the phenomenon leading to performance in the context of microfinance setting. The applicable theories are reviewed, concepts and their operational indicators identified and matched against existing empirical work and nascent knowledge gaps identified. The study finally, suggests a theoretical framework appropriate for progressing knowledge in the field of study together with the associated inferences for future research.
\end{abstract}

Keywords: first-mover advantage, innovation, innovation strategy, performance and regulatory framework

\section{Introduction}

The growth and expansion of strategic management discipline within the last two decades has been histrionic. According to Ansoff and McDonnell (1990), it is through Strategic management that firms are able to place and relate themselves to the environment to guarantee their sustained achievement and also protect themselves from shocks brought about by the fluctuating environment. One way a firm can safeguard itself from these shocks and equally increase efficiency is through innovations. According to Drucker (1985), innovation is a component of strategic planning and is a direct necessity for specific strategies. Thus, innovation functions as a means of generating new business with remarkable control mechanisms, value addition and risk reduction. Invention is crucial in improving productivity among numerous organizations and is revealed by enlarged productivity and market segment growth (Palmer \& Kaplan, 2007). Consequently, organizations that wish to remain competitive, enhance their growth capabilities and take advantage of accessible prospects that can attain all these by implementing innovation strategies.

Invention efficiency and technological advancement are linked to the strength of the firm's knowledge base, because if an organization has robust information base, it suggests an enhanced capability to focus innovation efforts resourcefully (Nelson, 1982). According to Davila, Epstein, and Shelton (2006) innovation is an essential element for persistent achievement and is a vital part of the business inventiveness. Successful organizations are currently the ones that implement innovative strategies by investing in research, development and commercialization of the emergent innovations. Execution of such a strategic option is likely to result in strategic moves that will register impacts in the market which requires decision makers to consider the timing of their moves that operationalize the strategy in the market (Keupp, Palmié, \& Gassmann, 2012). The timing is critical in capturing the market and sustaining competitive advantage. The timing of introduction of such strategic options has been the domain of discussion by scholars concentrating on the construct of first mover advantage. 
By deciding to enter the market first, the firm will embrace certain advantages. According to Golder and Tellis (2003), first mover advantage implies that firms that are able to identify and act first upon some identified opportunity in the business environment gain competitive advantage over their competitors. Pioneer advantages emanate from three main sources, namely technical knowledge, pre-emption of resources and purchaser swapping cost (Liberman \& Montgomery, 1988).

Within the micro enterprise sector, firms specializing in microfinance need to embrace innovative strategies so as to remain competitive in a rapidly ever changing business environment. The outcomes of innovative strategies are manifest through product, process, marketing and organization innovations. Firms that implement and commercialize innovative strategies will initiate moves that will see new products or services taken to the market. The timing of entry into the market becomes critical. By deciding to enter the market first, the firms will enjoy certain advantages like achieving a market position of being perceived as market responsive, creative and innovative. Thus, the strategic management literature focusing on the strategic option of innovation needs to integrate arguments based on the discourse derived from first mover advantage.

\subsection{Statement of the Problem}

Innovation strategies offer a strategic option that can be used to align organization's assets and competencies with prospects in the external environment in order to heighten survival and long term success of an enterprise. Even though execution of such a strategic option is likely to result in strategic moves that will register impacts in the market which requires decision makers to consider the timing of their moves that operationalize the strategy in the market, the extant literature has pursued discussions on the construct of innovation strategy separately from that of first mover in spite of the implied indications that the two can be integrated into a strategic management phenomenon that will influence firm's performance.

A common experience in strategic management regarding this performance has been adoption of different indicators of performance in isolation when relating strategies with the construct of performance. Such an approach has been faulted for its limitations in that the diverse performance indicators tend to be of limited use if looked at in isolation particularly in the case for profitability indicators. To understand how an institution achieves its profits (or losses), the analysis also needs to take into account other indicators that illuminate the operational performance of the institution, such as operational efficiency and portfolio quality. In the case of the Micro finance sector, the extant literature indicates that appropriate measurement of their performance needs to consider integration of diverse indicators when relating strategies with performance. Owing to the continuing evolution, expansion and growing significance of microfinance sector, numerous scholars have researched on the sector but have however, not considered the effect of innovation strategy, first mover advantage and performance in the context of microfinance sector and those that have been done so far have not used multiple indicators of the performance construct. This paper therefore undertook to review the extant theoretical and empirical literature with a view to identifying the emergent gaps and suggest a theoretical model linking the constructs of innovation strategy, first mover advantage and Micro Finance Institution (MFI) Performance. The study was guided by three objectives. The First was to review the extant literature on innovation strategy, first mover advantage and MFI Performance; secondly the study identified the emerging theoretical and empirical gaps that present a call for future research and finally the study proposed a theoretical model for guiding future research.

Undertaking this study was considered significant in view of a number of considerations. First the study builds on the continuing academic dialogue in strategic management touching on the linkages between strategic options involving innovation and the emergent firm strategic behaviors that account for the timing of entry into markets to launch the outcomes of the innovation strategies. Secondly the study responds to the emerging call to link firm strategies to performance using a comprehensive set of indicators to the construct of performance. Using evidence from the extant theoretical and empirical literatures, the study identifies several indicators of performance for MFIs and proposes a theoretical link of these indicators with the adopted strategic option of innovation. Lastly, the study suggests a theoretical model that future research can adopt to empirically investigate the relationship between innovation strategy and MFI Performance as well as the role of pioneer advantage on this existing relationship.

\section{Literature Review}

\subsection{Conceptual Review of Literature}

In order to respond to the study objectives, the paper presents a synopsis of the constructs of innovation strategies, first mover advantage and performance in the context of microfinance sector and theories on which the constructs are grounded. 


\subsubsection{Innovation Strategies}

The current understanding of innovation that raises ground for innovation strategies of the firm is traced to the origin of the firm. Considering this theoretical route provides a basis for explaining why Firms need innovation to succeed, survive and gain sustainable competitive advantage (Jimenez \& Sanz-Valle, 2011; Bell, 2005; Cho \& Pucik, 2005; Gopalakrishnan \& Damanpour, 1997; Damanpour, 1996; Fiol, 1996; Wolfe, 1994). The term innovation comes from the Latin word - innovare - meaning 'to make something new'. According to Robert and Tucker (2008) invention entails coming up with concepts and bringing them to existence. The purpose of innovation is to create new customer value. UK Department of Trade and Industry (2007) assumes that innovation is a process of spinning opportunity into new ideas and of putting these into widely used practice. According to Katz (2007) innovation is "the successful generation, development and implementation of new and novel ideas, which, introduce new products, processes and/or strategies to a company or enhance current products, processes and/or strategies leading to commercial success and possible market leadership and create value for stakeholders, driving economic growth and improving standards of living"

Dodgson, Gann and Salter (2008) conceptualize invention strategy as the idea that supports organizations to choose in an increasing and supportable way the kind of innovation that best fits firm's goals, shapes resolution on how assets are to be utilized to meet organization's goals and thus delivering value and enhance competitive advantage. An innovation strategy is based on the firm's innovation system. An innovation strategy is "an incrementalist, functional, predetermined plan governing the allocation of resource to different types of innovations in order to achieve a company's overall corporate strategic objectives and, a decision framework guiding a company about when and how it should selectively abandon the past and/or change its corporate strategy and objectives in order to focus on the business of the future" (Katz, du Preez, Schutte, 2010).

Implementation of an innovation strategy may call for change in the business model an organization is using and may involve change in processes, products and services and production processes (Lindgren, 2012). The state of literature has brought forth different types of innovation strategies touching on product innovations, process innovations, marketing innovations and stimulus innovations. Innovation strategies entail invention of products, services, or administrative procedures that no other firm has introduced. Innovation strategies in the context of SME sector have been conceptualized by the product innovations, process innovations, market innovations and stimulus innovations.

\subsubsection{Performance in the Context of Microfinance Sector}

Organization's performance is the motivating power of each institution. The essence of existence of firms is to stay lucrative and solvent (Boon, 2011). According to Lin, Peng and Kao (2008), organizational productivity is a result attained in achieving both internal and external objectives of an organization. Accomplishment of any firm depends on its productivity echelons and the capacity to have, sustain, and expand in its productivity intensities (Koontz, 2012). Firm's productivity is of paramount importance as it determines the existence or death, success or failure, growth or degeneration and degree of investments. Thus, one of the critical aspects of the management of a company is performance evaluation (Obonyo, 2008).

Robinson (2003) asserts that productivity could be evaluated in two ways: objectively or subjectively. Objective evaluations are generally grounded on financial information such as financial results, while subjective dimensions are better than objective evaluations since accounting information is not readily accessible and not usually dependable since they could be manipulated by owners for various reasons (Miller, 2007). Alam, Raza and Akram (2011) argue that organization's productivity is conceptualized as a multidimensional concept that comprises of four components: client-focused productivity with client's satisfaction as an indicator; product and financial productivity, market productivity operationalized through income, returns, market position, incomes per share and human capital productivity operationalized through staff fulfillment; and firm's efficiency. In the context of Micro finance sector, Helms (2006), observed that performance measurement is a tool for managing Micro Finance Institutions (MFIs) and is a requirement for sustainability and thus assessing the performance of an MFI is about examining its development towards accomplishing goals. The construct of performance in the context of microfinance sector has therefore been operationalized using four key indicators: Portfolio quality, efficiency and productivity, financial management and profitability.

Portfolio quality is a key component of analysis, since the biggest source of risk for any financial institution exists in its loan portfolio. Stauffenberg, Jansson, Kenyon and Badiola (2003), argued that loan portfolio is by far a microfinance's biggest asset that are typically not backed by bankable collateral, the quality of the portfolio is absolutely crucial. Portfolio quality and associated risks are operationalized by portfolio at risks, write offs, provision expenses and risk coverage. The most widely used measure of portfolio quality in the microfinance 
industry is Portfolio at Risk (PAR), which measures the portion of the loan portfolio in arrears as a percentage of the total portfolio. The second performance indicator is efficiency and productivity which shows how well the institution is streamlining its operations. Productivity indicators reflect the amount of output per unit of input, while efficiency indicators take into account the cost of the inputs and the price of outputs. Since these indicators are not easily manipulated by management decisions, they are more readily comparable across institutions (Stauffenberg et al, 2003). Efficiency and productivity indicators are operationalized by operating expenses, cost per borrower, personnel productivity and loan officer productivity.

The third financial management indicator assures that there is enough liquidity to meet an MFI's obligations to disburse loans to its borrowers and to repay loans to its creditors. The importance of adequate liquidity, and hence of financial management, grows further if the MFI is mobilizing savings from depositors (Rosenberg 2009). Financial management can also have a decisive impact on profitability through the skill with which liquid funds are invested. Financial management of a microfinance institution has been operationalized by funding expense, cost of funds and debt/equity. Profitability measures, such as return on equity, return on assets and portfolio yield, tend to summarize performance in all areas of the company. Return on Assets (ROA) is calculated as net profit/total assets. ROA shows the ability of the management to acquire deposits at a reasonable cost and invest them in profitable investments (Ahmed, 2009). The higher the ROA, the higher the profitability. Return on Equity (ROE) is another performance indicator. This is calculated as net profit/ total equity. ROE is the most important indicator of a bank's profitability and growth potential from the shareholders/investors perspective. It is the rate of return to shareholders/investors or the percentage return on each unit of equity invested in the bank (Ahmed, 2009). If portfolio quality is poor or efficiency is low, this will be reflected in profitability.

\subsubsection{First Mover Advantage}

Pioneer advantages represent a crucial perspective in the strategic management literature and in business practice. The concept, first mover is analogous with the term pioneer (Golder \& Tellis, 2003). From extant literature, numerous thoughts have been raised about conceptualization of pioneer, how and when pioneer benefits arise. The commonly utilized description of pioneer in the literature is based on the rank by which organizations enter markets; the first organization or brand to enter market being the pioneer (Durand \& Coeurderoy, 2001). According to Golder and Tellis (2003) a first mover is an organization that is first to commercialize a brand.

An important question that arises is how pioneer advantage can be derived from innovation strategies. A critical examination of diverse literature enlightens us on how a pioneer advantage arises from executed innovation strategies. From the analysis, two considerations arise which explain various scenarios. First, previous studies have proposed how business persons notice possible gains and losses connected with exploring prospects as the key defining component of entrepreneurial choices (Read, Dew, et al., 2009; Read, Song, \& Smit, 2009; Song, Di Benedetto, \& Zhao, 2008). Secondly, understanding innovation strategies per se is not enough to determine the entrepreneurs' behavior because it is the choice that matters. Entrepreneurs encounter some particularly serious risks and challenges. Due to their limited human and financial resources, they must decide whether they should enter the market, and whether they would be able to sustain an early competitive advantage (Durand \& Coeurderoy, 2001; Lévesque \& Shepherd, 2004; Lieberman \& Montgomery, 1988).

There are different forms of first mover advantage. First, some authors are of the opinion of using the line of technological leadership. Liberman and Montgomery, (1988) argued that when technological leadership originates from effective copyrights or R\&D, the pioneer may attain benefits by patenting technology or maintaining it as trade secrets. The motive to embrace copyrights is to shield the organization which undertook expensive exploration and development of new brands. Pioneers may utilize copyrights to attain and safeguard technological headship (Golder \& Tellis, 2002). Kanniainen (1992) asserted that effective R\&D projects improve performance of the pioneer's quantifiable assets. Technological leadership may play a critical function in high technology businesses but might be of slight significance in low technology divisions. This is essentially due to brief lifespan of numerous brands from the low technology segment.

The second aspect touches on pre-emption of scarce assets. According to Liberman and Montgomery (1988), if a pioneer organization obtains some kind of rare resources then that organization may attain advantages owed to the achievement. Resources might be in the form of location for instance geographic or shelf space or production sites. These kinds of resources might be acquired in advance by the pioneer if superior information is acquired prior to development of the market and can thus, purchase resources at prices that are less than the prices after the advancement. Thirdly, it has also been indicated that pioneering advantages may arise from buyer's swapping cost which is the expense for clients to change from one product to another. According to Lieberman and 
Montgomery (1998) consumers might make purchaser's swapping costs, as they form an experience with the pioneer's product. Consumer swapping cost might result into advantages for pioneer organizations since followers must spend more to charm clients. Swapping expenses might rise from operation costs or investments that the purchaser creates while adjusting to the merchant's brand. Michael (2003) asserts that the pioneers might generate consumer swapping expenses due to assumption of human or physical capital. This type of consumer swapping expenses appears small in some industries like guesthouses, restaurants and retail stores. According to Mueller (1997) swapping costs can arise from seller specific knowledge by the consumer, if the client adjusts to features of a product and its provider, he may discover that it is expensive to swap to a different product. Nakata and Sivakumar (1997) asserted that the pioneer's purchaser swapping cost advantage may not be as big as assumed. Consumers may discover the price gap between the first mover's brand and local substitutes to be so big that they will migrate from the pioneer to the local substitutes. This will not be of course an instance for fewer price-sensitive consumers, keen to pay more for high and reliable quality or for image motives. Consumer swapping cost in manufacturing products market often disperses over time as consumers become conversant with rival brands. Thus pioneer's advantage through consumer swapping expenses might be effective in buyer-products markets than in industrial-products markets (Zantout \& Chaganti, 1996).

Lastly, product loyalty is an inclination for a trademark that advances from a customer's previous consumption of the product (Golder \& Tellis, 2001). A pioneer has a huge benefit in shaping preferences of the customers. Pioneer's brand will form the base for contrast with follower's brands. As long as the pioneer's brands are pleasing to clients, they will outclass the follower's brands. This type of product allegiance may be predominantly robust for low price convenience products where advantages of getting superior products are seldom good enough to warrant extra search costs that must be gained (Lieberman \& Montgomery, 1988). If consumers are contented with certain firm's brands they will purchase products of the same brand when it is time to re purchase a product.

\subsubsection{Regulatory Framework}

The operationalization of innovation strategies requires new products or services that a firm takes to the market. Rogers (1962) using the diffusion of innovation approach introduced the role of the society in which the innovation is marketed. The investor needs to appreciate the contextual reality of the social setting of the system in which innovations are conceived and implemented. According to the institutional perspective, the society has norms, value systems and rules that can constraint the decisions and actions of business organizations. The constraints are normally felt through enacted laws and regulations and so raising the need to consider rules and settings in which an innovation is commercialized.

According to Edinburgh (2003), regulatory framework is a structure of guidelines and the means used to administer them. They are usually enacted by industry regulators to control the specific activities. They may be accompanied by procedures, standard commands and guidelines. It entails all applicable legislative documents (acts, regulations, annexes) and designates the agency or body accountable for administering the framework. Scott (2004), indicated that there is need to recognize that institutional environments are not monolithic, but often varied and conflicted, with both positive and negative impacts on the organizational performance, depending on the exact nature of the environmental factors. The Institutional environment includes government laws and regulations, industry self-regulation, organizational culture and national culture. The institutional environmental forces are therefore expected to influence the development of innovation strategies, first mover advantage and performance in the context of microfinance sector.

From the conceptual literature, there are two types of regulation: Prudential and non-prudential. According to Christen, Lyman, and Rosenberg (2003) prudential regulation aims precisely at shielding a financial system as a whole as well as protecting the safety of small deposits in individual institutions. Safe guarding the well-being of deposits affords the justification for enhanced supervision of microfinance firms. According to Christen, Lyman and Rosenberg (2003), provident rules should largely be triggered when a microfinance institution receives deposits from the general public.

\subsection{Conceptual Issues}

From the conceptual review, a number of issues emerge. First, is the fact that the review has provided an understanding of the constructs of innovation strategies, first mover advantage and performance in the setting of microfinance sector. The Construct of innovation strategy has been defined in terms of invention of products, services, or administrative procedures that no other firm has introduced (Roger, 1983) and is operationalized through several indicators: product, process, marketing and organization innovations. According to Peterson (1993), first mover advantage is a firm which is first to apply a particular strategy within the setting of specified 
scope. The construct has been operationalized by the indicators of technological knowledge, buyers switching cost and preemption of scarce resources. The construct of performance in the micro finance sector has been defined by Helms (2008) using four indicators of Portfolio quality, efficiency and productivity, financial management and profitability. The regulatory framework has been operationalized through Laws and legislations; Microfinance Act (2006), CBK prudential guidelines and Institutional environment identified from empirical literature for the construct of regulatory frame work.

Secondly, in examining these constructs from the diverse authors who have contributed towards their conceptual description, it is observable that there is a relatively high degree of consensus on the understanding of the constructs of innovation strategies, first mover advantage and performance in the context of microfinance sector. In addition, given the practical nature of strategic thinking and strategic management, it is necessary for scholars to examine how these constructs have been applied in diverse sectors of economy. It is the view of this paper, that empirical studies undertaken by researchers using these constructs will give insights on how the constructs have been used and applied in strategic management. Reviewed empirical studies have utilized some of these concepts to guide conceptualization in strategy research. For instance, Newman, Prajogo, and Atherton, (2016) assessed influence of market orientation on innovation strategies. Outstanding concepts in the study are innovation strategies and market orientation. Bedia, Lo'pez-Ferna'ndez and Piqueres (2011) researched on complementarity between innovation activities and innovation performance. The study was operationalized by concepts of innovation activities and innovation performance. Muck and Heimeshoff (2012) carried out a study on first mover advantage in mobile telecommunications. The study brought the construct of first mover advantage. Gathige (2013) assessed impact of regulations on productivity of deposit-taking savings and credit co-operatives in Kenya and found out licensing and governance regulations had strong positive effect on membership of deposit-taking saccos. Mustafa and Saat (2013) assessed microfinance performance measurement by introducing a new performance measurement framework. Shu and Oney (2014) studied outreach and performance analysis of microfinance institutions in Cameroon. Sanfeliu, Royo, and Clemente (2011) evaluated performance of social and non - profit microfinance institution (MFIs) through an application of multicriterion methodology. Astawa, Sukawati, Triyuni and Abdi (2015) assessed performance of microfinance institution in harmony cultural perspective in Bali. Building on these early works, numerous studies have further explored the links to other broader aspects such as innovation strategies, market orientation, first mover advantage, organizational context, and environmental conditions. For instance, Newman, Prajogo, and Atherton, (2016) linked market orientation to innovation strategies. Casprini, Massis, Di Minin, Frattini and Piccaluga (2017) studied how family owned firms execute open innovation strategies on performance. Heimeshoff (2012) examined first mover advantages in mobile telecommunications using evidence from OECD countries. While Gathige (2013) assessed impact of regulations on performance of deposit-taking savings and credit co-operatives in Kenya. Aswani (2013) studied effect of strategic innovation on performance of public universities in Kenya. Muita (2013) examined innovation strategies and competitive advantage in the telecommunication industry. Mwangi (2013) studied innovations and financial performance in the financial industry in Kenya. Kimani and Kibugo (2016) assessed effect of financial innovations on performance of microfinance institutions in Nakuru Town, Kenya.

The reviews indicate that even though the constructs have been applied in empirical work, the manner in which the operationalization was done may have gone beyond the scope of the current conceptual understanding and in addition, the studies failed to integrate more than two of the constructs in a single study. In view of this, the third issue that arises is that of exploring the theories that underpin the constructs. It is apparent that while the authors have attempted to provide a diversity of descriptions, they have not provided theoretical underpinning for their descriptions. It is therefore, essential for scholars to consider the theoretical underpinnings to the constructs and the phenomenon they bring about in strategic management. This observation is important in view of the fact that new pieces of knowledge need to be compared against existing theoretical models in order to provide direction on how a particular discipline needs to be undertaken.

\subsection{Review of Relevant Theories}

The conceptual review has paid attention to the nature of the main perspectives in the conceptualization originating from innovation strategies to generate a phenomenon leading to performance in the context of microfinance setting. This debate has raised issues that call for evaluation of the applicable theories that can expound on this phenomenon. Close analysis of the broad literature indicates that a broad range of theories from a multidisciplinary spectrum are required to not only comprehensively explore the nature of the concepts but also the phenomenon they bring about in strategic management research. The study therefore, considered the postulates and contributions of: Schumpeter theory of innovation, balanced scorecard theory, Institutional theory, 
regulation innovation theory and game theory.

\subsubsection{Schumpeter Theory of Innovation}

The theory was developed by Joseph Schumpeter, Austrian American economic and political thinker in 1934. Schumpeter asserts that invention is the motivating force for development. Five indicators of innovation were suggested in his definition: production of innovative products or qualitative enhancements in current products, use of innovative industrial practice, new market openings, diversification of sources of raw materials and other innovative inputs and systems of industrial establishments (Vyas 2009).

Schumpeter opined that businesses can generate prospect for new returns with their inventions. In turn, a batch of followers enticed by huge earnings would start trend of investments that would eat away the revenue margin for the invention. On the other hand, before the economy could equilibrate a new invention or set of inventions, hypothesized as Kondratiev cycles, would appear to start the corporate sequence over again.

Schumpeter underscored the function of entrepreneurship of pursuing prospects for new value addition events which would improve and change the spherical stream of revenue with reference to difference between innovation and discovery on one hand and invention, commercialization and entrepreneurship on the other. This isolation of innovation and invention defined the classic nineteenth century established approach of innovation, in which independent innovators normally nurtured discoveries as potential involvements to entrepreneurial organizations. Schumpeter further viewed inventions as perpetual gales of creative destruction that were indispensable forces motivating growth rates in a capitalist system.

Schumpeter's philosophy advanced to the level that researchers distinguished his early thinking where invention basically relied on remarkable people/businesses keen to take on extraordinary risks as an act of determination. The theory differentiated between the businesspersons whose inventions form environments for profitable novel ventures and the financiers who make credit to finance creation of the new enterprises. Author's brief deliberations of historical incidences of inventions in the field of banking might appear to propose a positive function for financial inventions in bankrolling the entrepreneurial enterprises that produce the primary wave growth spurts. The spread of joint stock banking was mentioned as one of the most significant inventions that happened in the early 1800s (Schumpeter, 1939).

Reflecting on innovation Strategies, first mover advantage and performance in the context of microfinance, the postulates of the theory point to the fact that organizations may attain competitive advantage and boost their productivity through innovative strategies and being the pioneer to introduce a product or process in the market. The theory is linked to innovation strategies since it addresses crucial questions about how organizations should innovate to attain the desired performance objectives. From the arguments of the theory, we can be able to extract the following types of innovations: product innovations, process innovations and marketing innovations which can serve as operational indicators of the construct of innovation strategies.

\subsubsection{Balanced Scorecard Theory}

The proponents of the model are Robert Kaplan and David Norton in 1992. The balanced scorecard model emerged out of acknowledged want to quantify achievement on more than just fiscal reports. The balanced scorecard gives an outline and explanation that allow one to define strategy in a consistent way. The ultimate objective behind balanced scorecard model is to quantify the elements that generate value for an enterprise and directly affects its capacity to succeed. Balanced score card measures a wide range of indicators cutting across four areas: financial, customer, internal and learning perspectives.

The first foundation is the financial aspect which tends to be historical, and does not disclose the present state of the business situation and the projections of the future performance. Nevertheless, financial measures are still significant since there is no surety that improved operating performance will certainly lead to financial success. The financial performance such as profitability of an enterprise is important to its accomplishment, therefore cannot be dismissed. The objectives in the financial aspect should serve as the motivation for objectives in all the other elements. Indicators are profitability, return on assets, return on investment, revenue, and cash flow (Kaplan \& Norton, 1992).

The second foundation is client aspect which focuses on key actions and practices that are necessary to enhance the firm's effort to shine at providing value anticipated by the customers. On the other hand, dismal performance in critical business procedures can lead to decline in customer satisfaction and eventually in profit margins. These measures function as central guidelines for managers to concentrate on pertinent internal operations that will assist in meeting customers' expectations. Kaplan and Norton (1992) assert that firms should concentrate on business practices that have great impact on customer satisfaction and are obligated to shine and contest in their 
industry. Classic measurements within this aspect concentrate on customer retention, market segment, client acquisition, client satisfaction, and profitability.

The third is internal aspect which centers on the practices within the firm that are pertinent in achieving client and shareholder objectives. Goals and measures of this aspect are established after the fiscal and client viewpoints are defined. Classic measurements within this aspect concentrate on invention, operations, and post-sale service. The aim of the internal business perspective is to define the key business practices that generate and supply the goods and services of the organization to the customers at the same time develop measures to ensure that these processes are working well.

The fourth foundation is innovation and learning perspective which defines the organization's ability to persistently progress and innovate. This is the base of any strategy and centers on the human and intangible assets of the firm. The learning perspective concentrates on formulating goals and actions to encourage learning within a firm. This perspective ponders on employee endowment, competences, information systems, motivation and alignment. The intentions in this viewpoint drive accomplishment of those in the first three foundations. Each business determines its own performance indicators. Scorecard application offers the firm with the tools that transform strategy into a scorecard, communicate it throughout the institution, assess progress towards attaining defined goals, notify key individuals automatically about scorecard position, and establish the source of problems (Abdul Moneim, Jaber Matarneh, \& Akour, 2017).

\subsubsection{Institutional Theory}

There are several views by management scholars on the institutional theory. According to Powell and DiMaggio (2012), the concept of 'institutions' means "the new institutionalism in firm's theory and sociology comprising a rejection of rational-actor models, an interest in enterprises as antecedent variables, a shot towards cognitive and cultural descriptions, and a concern in properties of supra-individual units of analysis that cannot be reduced to aggregations or direct consequences of individuals' qualities or intentions.

In order to survive, enterprises must adapt to the rules and belief systems predominant in the environment (Meyer \& Rowan, 1977). Martinsons (1993) and Porter (1996) observe that even multinational corporations (MNCs) functioning in different countries with varying institutional environments will face varied pressure and that some of those pressure in host and home organizational environments wield essential influences on the competitive strategy as well. Zaheer (1995) further observe that institutionalism also affects human resource management practices. Scott (2004) is of the view that institutional theory centers on the deeper and more resilient perspectives of social structure. Authoritative undocumented rules for social behaviour are molded by institutions via structures, schemes, regulations, norms, and routines (Scott, 2004).

According to Dacin, Goodstein and Scott (2002), institutions drive the changes in interaction across all levels, but the institutions are also subject to change in character and potency over time. There is considerable evidence that organizations in different kinds of economies react differently to similar challenges. Social, economic, and political aspects constitute an institutional structure for a particular environment, which offers enterprises with advantages and disadvantages for engaging in specific kinds of activities there. Enterprises incline to perform more efficiently if they receive institutional support. Therefore, organizational environment moderates between strategic capabilities and performance of the organization, including the achievement of competitiveness. However, the effect of the institutional environment on firm competitiveness is bound to be different for each business environment. Campbell (2007) argues that institutional theory shapes the behavior of firms to behave in a socially responsible way. The author adds that the several conditions mediate the corporate behavior including, public and private regulation, independent firms that monitor corporate behavior, institutionalized norms of appropriate corporate behavior and organized dialogues among their various stakeholders.

The environmental forces that exert pressure on the organization include government laws and regulations, industry self-regulation, national culture and organizational culture. Brammer, Jackson, and Matten (2012) argue that the institutional theory explains the contradictory behaviour of organizations between the "liberal notion of voluntary engagement" and the contrary implications of socially binding responsibilities. Institutional theory is therefore expected to moderate the firm strategic behaviour that involves interaction between innovation strategies and performance in the context of microfinance sector. The theory is linked to the construct of regulatory framework since it addresses environmental aspects and their influence on the performance of the organization. From the argument of the theory, we can be able to extract the following components of environmental framework: government laws and regulations, industry self-regulating, industry self-regulation, national culture and organizational culture which can serve as operational indicators of the construct of regulatory frame work. 


\subsubsection{Regulation Innovation Theory}

Scylla (1982) is accredited with inventing the theory which describes financial innovation from the viewpoint of economic development history. The theory suggests that financial innovation bonds with social regulation closely, and it is a regulation transformation which has common effect and causality with economic regulation. Scylla (1982) assumed that it was very hard to have space of financial innovation in the premeditated economy with stern control and in the pure free-market economy, so any variation brought about by regulation variation in financial system can be considered as financial innovation. Innovative activities can only appear in the market economy controlled by government. When government's involvement and the management have stalled the financial activities, there will be numerous types of financial innovation which aim to circumvent or get rid of government controls.

The game between the market and government finally form the spiral development process, namely, control-innovate, controls again-innovates again. This theory extended the scope of financial innovation; government activity is also considered as the origin of financial innovation. But it regards regulation innovation as one part of financial innovation. Especially, it regards rules and regulations which are utilized to control as financial innovation. The financial control is the obstructive force of financial innovation, so rules and regulations which are regarded as the symbol of financial control should be the direction of financial reform and innovation (Scylla 1982). The theory is linked to both constructs of innovation strategies and regulatory framework since it addresses key aspects of the organization's prevailing environment; rules and regulations that government has put in place to regulate the industry and innovation strategies that firms invent to circumvent or get rid of government controls. From the argument of the theory, we can be able to extract the following concepts: financial innovation and social regulations which can serve as operational indicators of the constructs of innovation strategies and regulatory framework.

\subsubsection{Game Theory}

Game theory is the practice of modeling the strategic interaction (cooperation, conflict,) of two or more players or decision makers who are cognizant that their actions affect each other. Game theory is a decision making choice against uncertainties (Friedman, 1986; Camerer, 2003; Rasmusen, 2006). It is a skill utilized to resolve the hitches of competitions where conflict of interest rises among the decision makers (Fudenberg \& Tirole, 1991; Eichberger, 1993; Herath, 2006). According to McNulty (2014), any time we have a situation with two or more players that comprises known payouts or quantifiable consequences, we can use game theory to assist determine the most likely results. The author of this mathematical theory of games was John von Neumann and Oskar Morgenstern (1944).

According to McNulty (2014), a "game" in game theory is a wholly explicit structure which personifies each player's set of payoffs, actions, and possible outcomes under given set of rules of playing. Under such conditions, rational players work in such a way, that they maximize the expected value of their utility. The critical components of a game are players, actions, information, strategies, outcomes, payoffs, and equilibrium. The players, actions and results are collectively referred to as the rules of the game. Game refers to any set of circumstances that has a result dependent on the actions of two of more decision makers ("players"). Players refers to strategic decision maker(s) within the context of the game.

Strategy is a complete plan of exploits a player will take given the set of circumstances that might arise within the game. Payoff is the overhead a player receives from arriving at a particular outcome. The payout can be in any quantifiable form. Information set is the available at a given point in the game usually applied when the game has a sequential component. While equilibrium is the point in a game where both players have made their decisions and an outcome is reached. The game theorist's goal is to utilize the rules of the game to forecast the equilibrium result of the game in terms of maximizing profits and improving market price fluctuations, which portend the sustainability of firms, the manufactures confronted with risks of market prices (Sahin et al., 2008). The theory is linked to the concept of first mover advantage since it addresses crucial questions about how organizations get payouts for their strategic decision made to attain competitive advantage.

\subsection{Theoretical Issues}

The reviewed theories have been found to be rich in content since indicators of the concepts of innovation strategies, first mover advantage and performance in the context of microfinance sector are identifiable. For example, innovation strategies and performance have been identified in Schumpeterian innovation theory. The construct of performance has been identified in the balanced scorecard theory while the constructs of regulatory framework and institutional environment have been identified in institutional theory. In addition, financial innovation, social regulation, regulation innovation have been identified in regulation innovation theory. Over 
and above these, it is observable that the postulates of the theories display complementarities in explaining diverse constructs that underlie firm strategic behaviour. Such complementarities draw the attention of researchers for purposes of conceptualization and theorizing in informing empirical work.

Numerous empirical efforts have utilized some of these theories to guide conceptualization in strategy research. For example, Newman, Prajogo, and Atherton, (2016) reviewed RBV theory and agency theory to explain influence of market orientation on innovation strategies. The study was carried out in Italy. Bedia, Lo'pez-Ferna'ndez and Piqueres (2011) utilized absorption capacity theory to expound on complementarity between innovation activities and innovation performance; Muck and Heimeshoff (2012) used theory of innovation to explain first mover advantages in mobile telecommunications; Kariuki (2014) used Schumpeter theory, Stakeholder theory, Agency theory and organizational control theory to explain effect of strategic innovation on performance of mobile telecommunication institutions in Kenya; Aswani (2013) used theory of innovation to explain strategic innovation and performance of public university.

\section{The Call for a Theoretical Model}

The discussions so far have pointed to numerous issues that raise the need for a new theoretical model. These issues touch on: first, the complementarities that exist among diverse theories that underpin the constructs of innovation, first mover advantage and firm performance. Second, the disconnect between the conceptual understanding and the theoretical underpinning of the constructs. Third, is the need for integration of both the conceptual and theoretical perspectives in empirical work so as to give researchers an opportunity to practically establish how these constructs have been understood and operationalized in practice. Arising from three above is the need for a systematic and coherent manner in employing the constructs that integrate the theories and practical experience from empirical work to advance the extant knowledge into new frontiers. This requires that researchers develop new theoretical models upon which propositions at the abstraction level can be advanced and empirically tested as hypotheses in empirical work. Scholars have often resorted to basics of ontology and epistemology in addressing debates on how to advance knowledge (Nachmias \& Nachmias, 2004; Kerlinger \& Lee, 2000). For example, Wandiga, Kilika and James (2017) relied on the perspective proposed by Nachmias and Nachmias (2004) on the role of theory in research to advance a case for a new conceptual model connecting operations strategies, customer based competencies and firm performance in the context of knowledge intensive organizations. Therefore, the current study proposes a theoretical model for guiding empirical work in strategic management taking into consideration the constructs that underlie the phenomenon brought about by the constructs playing the roles of antecedent factor, intermediate state, ultimate state and contingent role. Thus, the current study proceeds to suggest a theoretical model for guiding empirical work in strategic management.

\subsection{The Proposed Theoretical Framework}

The proposed theoretical framework (figure 1) demonstrates the role of regulatory framework and first mover advantage on the link between innovation strategies and performance. The proposed model is anchored on the constructs of innovation strategies, first mover advantage regulatory framework and performance in the context of microfinance. 


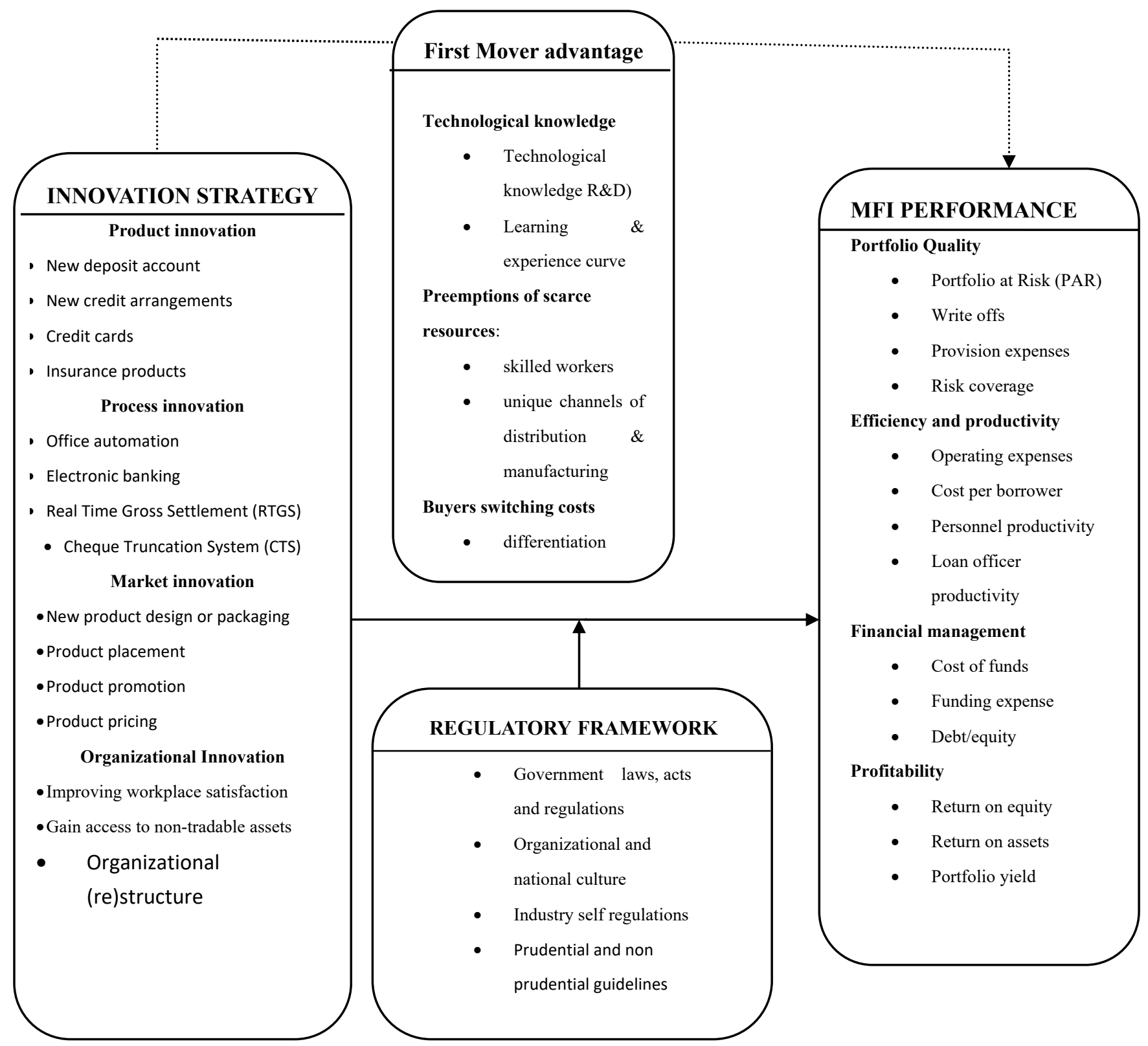

Figure 1. The conceptual framework of innovation strategies, first mover advantage and performance in the context of microfinance sector

\subsection{Propositions}

\subsubsection{Innovation Strategies and Financial Performance}

The antecedent factor in the proposed framework is innovation strategy. The construct has been operationalized using the indicators of product, process, market and organization innovation.

The strategy represents a viable strategic option that firms will consider in an endeavor to keep pace with changes in the external environment that call for adjustments in a variety of areas that will call for adjustments in the products, processes and systems in the organization that enhance the organizations response so as to appropriately fit in its environment. Undertaking such an option is guided by the fact that each organization wants to sustain its performance so that it is not eroded by the adverse effects of the external environment. The construct of performance in this case has been operationalized in terms of portfolio quality, productivity and efficiency, financial management and profitability. Consistent with the reasoning in strategic management justifying adoption of various strategic options, the expectation is that adoption of innovation strategies as a strategic option by firms will lead to enhanced performance of those organizations. Thus we propose that: 
Proposition 1: Adopted Innovation strategies by firms in the micro finance sector will enhance the performance of those firms.

\subsubsection{The Role of First Mover Advantage}

For firms that adopt an innovation strategic option, the timing of relevant strategic moves that operationalize this option and execute it in the market is key. Even though the option may carry with it a number of risks, innovative firms would prefer to make early moves that make each firm a pioneer in terms of the timing of its entry into the market to introduce new offers or processes. In line with Golder and Tellis (2003) argument that first mover/ Pioneer is the first to commercialize a product, employ a particular strategy within the context of specified scope thus capture the advantages of pioneering, they continuously scan the market to predict future trends, create pioneering advantages and shape market direction through employing innovative strategies. Since this pioneer advantage may be viewed as a form of competence or capability acquired by the pioneer, innovating firms will endeavour to scan their environments and ensure the proper timing of their introduction of their innovations to the market so that they sustain this market position of being perceived as the pioneer firm in the industry and market. Doing so ensures that the firm can reap advantages that result from preemption of scarce resources, buyers switching costs and technical knowledge. Attaining this market position of a pioneer and sustaining it would be a desire of the firm in view of competitive dynamics that may construe this perception of a pioneer as an area of strength that the firm would like to have as a condition to sustain its performance (Kotler, 2000). Thus, the desired ultimate state of performance emanating from the innovation strategy may be dependent upon this intermediate capability in the form of pioneer advantage in the short and medium terms. Based on these arguments, we propose that:

Proposition 2: Firms that adopt the strategic option of innovation strategy will gain an intermediate state of capability in the form of pioneer advantage that derives from deployment of the various forms of the innovation strategy.

Proposition 3: Even though the deployed innovation strategy influences the firm performance, the strength of such relationship will be dependent upon the earned intermediate state of capability in the form of pioneer advantage.

\subsubsection{The Role of Regulatory Framework}

The adopted innovation strategy within the firm is an internal resource the firm is deploying to generate desired results. The kind of results generated will however be conditioned by the setting in which the firm is operating. In a dynamic environment, firms are required to develop dynamic capabilities which enable the organization to create and deploy strategies that support sustained superior performance (Teece, 2007). These observations are based on the contributions of the RBV approach that has been criticized for ignoring the external environment of the firm. To complement the attempts by RBV, scholars are pointing at the need to integrate the external environment through the institutional and resource dependence perspectives (Meyer, 2006; Kilika, 2012). The institutional context in the proposed framework is represented by the Regulatory framework of the environment in which a firm operates and which can impact on the firm's operations directly or indirectly (Gonzalez-Torre \& Adenso-Diaz, 2010). In the case of a micro finance institution, the prevailing national culture, government laws, macroeconomic policies regulating the financial sector and industry self regulations are expected to exert pressure on firms to comply with. The compliance can have either positive or adverse effects on the operations of the firm and ultimately influence the results obtained from deployment of the innovation strategy. Thus, we propose that:

Proposition 4: Even though deployment of an innovations strategy will influence a firm's performance, the actual level of performance attained will be contingent upon compliance with the state of the regulatory framework prevailing in the respective industry.

\section{Conclusions}

The objective of this theoretical study was to review both existing theoretical and empirical literature, identify existing gaps in the phenomenon of innovation strategies, first mover advantage and performance in the context of microfinance sector and finally propose a conceptual model providing propositions for filling up the identified gaps. This study embraced a multidisciplinary centered approach to explore the nature of each construct, identify its operational indicators, the emergent theoretical and empirical gaps in order to suggest an integrated conceptual model for explaining the strategic behaviour involving innovation strategy, first mover advantage, performance and regulatory framework. The study thus proposed a suitable theoretical framework for adoption in guiding empirical work in strategic management involving the constructs of innovation strategy, pioneer 
advantage, firm performance and regulatory framework. Several propositions suggesting possible relationships among the constructs have also been made. The propositions however are based on conceptual and theoretical considerations and lack the needed empirical support. The authors are of the view that future endeavors in strategic management need to consider these propositions for adoption and testing in an empirical work. Researchers in strategic management will need to develop primary data collection tools based on the operationalized indicators of the constructs in the proposed framework and obtain data for testing the propositions as hypotheses in empirical work.

\section{References}

Abdul Moneim, U., Jaber Matarneh, A., \& Akour, S. (2017). The Impact of Cognitive Integration between the Traditional Balanced Scorecard and the Information Technology Balanced Scorecard on the Entrepreneurship Value of the Jordanian Public Shareholding Industrial Companies. International Journal of Business and Management, 13(1), 153. https://doi.org/10.5539/ijbm.v13n1p153

Alam, H. M., Raza, A., Scholar, M. C., Session, E. N., \& Akram, M. (2011). A Financial Performance Comparison of Public Vs Private Banks: The Case of Commercial Banking Sector of Pakistan. International Journal of Business and Social Science, 2(11), 56-64.

Atalay, M., Anafarta, N., \& Sarvan, F. (2013). The Relationship between Innovation and Firm Performance: An Empirical Evidence from Turkish Automotive Supplier Industry. Procedia - Social and Behavioral Sciences, 75, 226-235. https://doi.org/10.1016/j.sbspro.2013.04.026

Auh, S., \& Menguc, B. (2005). Top management team diversity and innovativeness: The moderating role of interfunctional coordination. Industrial Marketing Management, 34(3), 249-261. https://doi.org/10.1016/j.indmarman.2004.09.005

Bell, J. (2005). Doing your Research Project. British Journal of Educational Technology (Vol. 3rd). Retrieved from http://books.google.com/books?id=aroefdSRc8AC\&pgis=1

Borza, A., Richter, C., \& Bordean, O. (2011). Innovation and Entrepreneurship in a Global Economy: Economics, Innovation, Competition and Social Change. International Network for Economic Research (INFER), 1, 4. https://doi.org/10.1186/s40497-015-0022-y

Brammer, S., Jackson, G., \& Matten, D. (2012). Corporate Social Responsibility and institutional theory: new perspectives on private governance. Socio-Economic Review, 10(1), 3-28. https://doi.org/10.1093/ser/mwr030

Buyl, T., Boone, C., \& Hendriks, W. (2014). Top management team members' decision influence and cooperative behaviour: An empirical study in the information technology industry. British Journal of Management, 25(2), 285-304. https://doi.org/10.1111/1467-8551.12004

Camerer, C. F. (2003). Behavioural studies of strategic thinking in games. Trends in Cognitive Sciences, 7(5), 225-231. https://doi.org/10.1016/S1364-6613(03)00094-9

Campbell, J. Y. (2008). Viewpoint: Estimating the equity premium. Canadian Journal of Economics, 41(1), 1-21. https://doi.org/10.1111/j.1365-2966.2008.00453.x

Chandrasekaran, D., Arts, J. W. C., Tellis, G. J., \& Frambach, R. T. (2013). Pricing in the international takeoff of new products. International Journal of Research in Marketing, 30(3), 249-264. https://doi.org/10.1016/j.jiresmar.2012.09.008

Coeurderoy, R., \& Durand, R. (2004). Leveraging the advantage of early entry: Proprietary technologies versus cost leadership. Journal of Business Research, 57(6), 583-590. https://doi.org/10.1016/S0148-2963(02)00423-X

Dacin, M. T., \& Scott, W. R. (2002). Institutional Theory and Institutional Change : Introduction To the Special Research Forum, 45(1), 45-57.

Dew, N., Read, S., Sarasvathy, S. D., \& Wiltbank, R. (2015). Entrepreneurial expertize and the use of control. Journal of Business Venturing Insights, 4, 30-37. https://doi.org/10.1016/j.jbvi.2015.09.001

Gibbons, R. (2013). Cyert and March (1963) at Fifty: A Perspective from Organization Economics. National Bureau of Economic Research, NBER Organ(1963), 1-11. Retrieved from http://web.mit.edu/rgibbons/www/Gibbons CM at 50 v6.pdf

Helms, B. (2006). Access for All: Building Inclusive Financial Systems. [e-book] Washington: The World Bank. https://doi.org/10.1596/978-0-8213-6360-7 
Hittmár, Š., Varmus, M., \& Lendel, V. (2014). Proposal of Model for Effective Implementation of Innovation Strategy to Business. Procedia - Social and Behavioral Sciences, 109, 1194-1198. https://doi.org/10.1016/j.sbspro.2013.12.611

Janson, T.., Craig, D., Crookston, N., Garton, O., Haskins, D., Hyatt, P., ... Mcdonald, L. (2003). Performance Indicators for Microfinance Institutions: A Technical Guide. MicroRate \& Inter-American Development Bank, 3.

Kanniainen, V., Pääkkönen, J., \& Schneider, F. (2004). Fiscal and Ethical Determinants of Shadow Economy: Theory and Evidence Fiscal and Ethical Determinants of Shadow Economy : Theory and Evidence, 17(30).

Kaplan, R. S., \& Norton, D. P. (1996). Linking the Balanced Scorecard to Strategy. California Management Review, 39(1), 53-79. https://doi.org/10.2307/41165876

Keupp, M. M., Palmié, M., \& Gassmann, O. (2012). The Strategic Management of Innovation: A Systematic Review and Paths for Future Research. International Journal of Management Reviews, 14(4), 367-390. https://doi.org/10.1111/j.1468-2370.2011.00321.x

Kheder, A., Mustafa, A., Saat, M. M., Management, F., \& Skudai, U. T. M. (2013). Microfinance Institutions Performance Measurement : Introducing a New Performance Measurement Framework, 15(11), 1618-1628. https://doi.org/10.5829/idosi.mejsr.2013.15.11.11644

Kilika, J. M. (2012). Institutional context, collaboration, human resource development infrastructure and performance of Universities in Kenya. University of Nairobi:Unpublished Doctoral Thesis.

Kingdom, U., Cherotich, K. M., Sang, W., \& Shisia, A. (2015). Financial Innovations and Performance of Commercial Banks in Kenya. International Journal of Economics,Commerce and Management, III(5), $1242-1265$.

Kotler, P. (2000). Marketing Management, Millenium Edition. Marketing Management, 23(6), 188-193. https://doi.org/10.1016/0024-6301(90)90145-T

Lieberman, M. B., \& Montgomery, D. B. (1998). First-mover (dis) advantages: Retrospective and link with the resource-based view. Strategic Management Journal, 1125(June), 1111-1125. https://doi.org/10.1002/(SICI)1097-0266(1998120)19:12<1111::AID-SMJ21>3.3.CO;2-N

Lindgren, P. (2012). Business Model Innovation Leadership: How Do SME’s Strategically Lead Business Model Innovation? International Journal of Business and Management, 7(14), 53-66. https://doi.org/10.5539/ijbm.v7n14p53

McNulty, J., \& Akhigbe, A. (2014). Bank Performance and the Financial Crisis: Evidence from the Financial crisis. Applied Financial Economics, 24(1-3), 121-138. https://doi.org/10.1080/09603107.2013.868584

Meyer, J. W. (2006). Reflections on Institutional Theories of Organizations. The SAGE Handbook of Organizational Institutionalism, 790-812. https://doi.org/10.4135/9781849200387.n35

Nachmias,F.\& Nachmias, D. (2004). Research methods in the social sciences (English ). New York, NY: St. Martin's Press.

Nelson, R. R., \& Winter, S. G. (1982). An evolutionary theory of economic change. Cambridge MA Belknap (Vol. 93). https://doi.org/10.2307/2232409

Porter, M. E. (1996). Operational Effectiveness Is Not Strategy. Harvard Business Review, 74(December), 61-78. https://doi.org/10.1098/rspb.2008.0355

Rosenberg, R. (2009). Measuring Results of Microfinance Institutions Minimum Indicators that Donors and Investors Should Trac.pdf. CGAP Technical Guide, (June), 1-32.

Ruiz-Jiménez, J. M., \& Fuentes-Fuentes, M. del M. (2016). Management capabilities, innovation, and gender diversity in the top management team: An empirical analysis in technology-based SMEs. BRQ Business Research Quarterly, 19(2), 107-121. https://doi.org/10.1016/j.brq.2015.08.003

Sanfeliu, C. B., Royo, R. C., \& Clemente, I. M. (2013). Measuring performance of social and non-profit Microfinance Institutions ( MFIs ): An application of multicriterion methodology. Mathematical and Computer Modelling, 57(7-8), 1671-1678. https://doi.org/10.1016/j.mcm.2011.11.010

Sangwan, K. S. (2017). Key Activities, Decision Variables and Performance Indicators of Reverse Logistics. Procedia CIRP, 61, 257-262. https://doi.org/10.1016/j.procir.2016.11.185

Teece, D. J. (2017). Towards a capability theory of (innovating) firms: Implications for management and policy. 
Cambridge Journal of Economics, 41(3), 693-720. https://doi.org/10.1093/cje/bew063

Wandiga, E. N., Kilika, J. M., \& James, R. (2017). Linking Operations Strategies with Customer Based Competence and Firm Performance in the Context of Knowledge Based Intensive Sector: A Theoretical Review. International Journal of Business \& Management, 12(8), 234-248. https://doi.org/10.5539/ijbm.v12n8p234

Wanjiru, A. I. (2017). An Integrated Theoretical Framework on Corporate Strategy, Leadership and Firm Performance : A Research Agenda. The International Journal of Business \& Management, 5(1), 66-73.

Zaheer, S. (1995). Overcoming the Liability of Foreignness. Academy of Management Journal, 38(2), 341-363. https://doi.org/10.2307/256683

\section{Copyrights}

Copyright for this article is retained by the author(s), with first publication rights granted to the journal.

This is an open-access article distributed under the terms and conditions of the Creative Commons Attribution license (http://creativecommons.org/licenses/by/4.0/). 